in vivo $35: 653-661(2021)$

doi:10.21873/invivo. 12305

\title{
Beneficial Effects of Intermediate Dosage of Anticoagulation Treatment on the Prognosis of Hospitalized COVID-19 Patients: The ETHRA Study
}

\author{
GARYPHALLIA POULAKOU ${ }^{1}$, EVANGELOS DIMAKAKOS ${ }^{1}$, ANASTASIOS KOLLIAS ${ }^{1}$, \\ KONSTANTINOS G. KYRIAKOULIS ${ }^{1}$, VASILIKI RAPTI ${ }^{1}$, IOANNIS TRONTZAS ${ }^{1}$, CHARALAMPOS THANOS $^{1}$, \\ MAHMOUD ABDELRASOUL ${ }^{2}$, THEODORA VANTANA ${ }^{3}$, KONSTANTINOS LEONTIS $^{1}$, ELENI KAKALOU ${ }^{1}$, \\ KATERINA ARGYRAKI ${ }^{3}$, IOANNIS BARABOUTIS ${ }^{2}$, EVANGELOS MICHELAKIS ${ }^{4}$, \\ EVANGELOS GIAMARELLOS-BOURBOULIS ${ }^{5}$, KATERINA DIMAKOU ${ }^{6}$, GEORGIOS TSOUKALAS ${ }^{7}$, \\ ANGELIKI RAPTI ${ }^{8}$, EVANGELOS D. MICHELAKIS ${ }^{9}$ and KONSTANTINOS N. SYRIGOS ${ }^{1}$ \\ ${ }^{1} 3^{\text {rd }}$ Department of Internal Medicine, National and Kapodistrian University of Athens, \\ School of Medicine, Sotiria General Hospital, Athens, Greece; \\ ${ }^{2}$ Department of Internal Medicine, Divine Providence Hospital "Pammakaristos", Athens, Greece; \\ ${ }^{3} 1^{\text {st }}$ Department of Infectious Diseases, Sotiria General Hospital, Athens, Greece; \\ ${ }^{4} 2^{\text {nd }}$ Department of Internal Medicine, General Hospital of Nikaia, Piraeus, Greece; \\ $5^{\text {th }}$ Department of Internal Medicine, National and Kapodistrian University of Athens, Medical School, Athens, Greece; \\ ${ }^{6} 5^{\text {th }}$ Respiratory Medicine Department, Sotiria General Hospital, Athens, Greece; \\ ${ }^{7} 4^{\text {th }}$ Respiratory Medicine Department, Sotiria General Hospital, Athens, Greece; \\ ${ }_{8} 2^{\text {nd }}$ Respiratory Medicine Department, Sotiria General Hospital, Athens, Greece; \\ ${ }^{9}$ Department of Medicine, University of Alberta, Edmonton, Canada
}

\begin{abstract}
Background/Aim: To investigate the efficacy (prognosis, coagulation/inflammation biomarkers) and safety (bleeding events) of different anticoagulation dosages in COVID-19 inpatients. Patients and Methods: COVID-19 inpatients (Athens, Greece) were included. The "Enhanced dose THRomboprophylaxis in Admissions (ETHRA)" protocol was applied in certain Departments, suggesting the use of intermediate anticoagulation dosage. The primary endpoint was a composite of intubation/venous thromboembolism/death. Inflammation/coagulation parameters were assessed. Results: Among 127 admissions, 95 fulfilled the inclusion criteria. Twenty-one events (4 deaths, 17 intubations) were observed. Regression analysis demonstrated significant reduction of
\end{abstract}

This article is freely accessible online.

Correspondence to: Evangelos Dimakakos, MD, Ph.D., $3^{\text {rd }}$ Department of Internal Medicine, National and Kapodistrian University of Athens, School of Medicine, Sotiria Hospital, 152 Mesogion Avenue, Athens 11527, Greece. Tel: +30 2107763703, +30 2107763400, e-mail: edimakakos@yahoo.gr

Key Words: COVID-19, anticoagulation, thromboprophylaxis, prognosis, intermediate dosage. events with intermediate or therapeutic dosage [HR=0.16 (95\%CI=0.05-0.52) $p=0.002 ; H R=0.17(0.04-0.71) p=0.015$, respectively]. D-Dimer values were higher in those who met the composite endpoint. Intermediate dosage treatment was associated with decreased values of ferritin. Three patients (3\%) had minor hemorrhagic complications. Conclusion: Anticoagulation treatment (particularly intermediate dosage) appears to have positive impact on COVID-19 inpatients' prognosis by inhibiting both coagulation and inflammatory cascades.

Coronavirus disease 2019 (COVID-19) was first reported in Wuhan, China in December 2019 (1, 2). The novel coronavirus SARS-CoV-2 was recognized as the causative pathogen of the new viral illness with potentially fatal complications $(1,2)$. At the time of writing this manuscript, this novel coronavirus has caused more than $1,000,000$ deaths (3). In Greece, the first phase of the pandemic was almost completed as of May 4, permitting a gradual lift of lockdown measures thereafter (4). Despite the much-feared fragility of the National Health system due to the preceding ten-year financial crisis, a successful flattening of the epidemic curve was achieved (5).

SARS-CoV-2 causes asymptomatic infection or mild symptoms in the majority of infected patients; nevertheless, 
$5 \%$ of symptomatic patients may develop serious disease including Acute Respiratory Distress Syndrome (ARDS) and death $(1,2,6)$. Important cardiovascular complications have been recognized, particularly in patients with prior cardiovascular disease $(7,8)$. In addition, most fatal events among previously healthy individuals have been attributed to pulmonary embolism or disseminated silent microemboli (9, 10). Elevated D-Dimers and prolonged prothrombin time (PT) have been proposed as surrogates of SARS-CoV-2 mediated coagulopathy (11-13). Fatal events have been attributed mainly to excessive inflammatory response, involving vascular endothelium injury, and subsequent thrombosis and/or embolism (6, 10, 12, 14-17). Moreover, disseminated intravascular coagulation (DIC), has been recognized as an additional mechanism leading to possibly fatal complications (12, 18-20). Heparin has been shown to exhibit both antithrombotic and anti-inflammatory effects, thereby inhibiting both mechanisms of severe COVID-19 disease (21$25)$. Taking into consideration primary evidence and based on our previous experience with H1N1-related fatal pulmonary embolisms, we developed a local anticoagulation protocol and algorithm, named "Enhanced dose THRomboprophylaxis in all COVID-19 Admissions" (ETHRA) (21, 22, 26-28). The ETHRA Study was set to evaluate whether different dosages of anticoagulation treatment could potentially prevent adverse outcomes in COVID-19 patients hospitalized in general wards. Underlying mechanisms could be the inhibition of both procoagulant and inflammatory cascade. Shortly after initiation of our protocol, guidelines have been issued for the prevention of VTE and interruption of DIC cascade in hospitalized COVID-19 patients, arguing for the use of anticoagulation treatment, albeit in prophylactic doses (29-31).

\section{Patients and Methods}

Setting and study population. This is a retrospective analysis of prospectively collected data from consecutive patients admitted in two reference Hospitals for COVID-19 in Athens Metropolitan area, during the first six weeks of the epidemic in Greece. Sotiria is a 750bed tertiary reference hospital for respiratory diseases, which held more than $60 \%$ of the COVID-19 inpatient load for the first two months of the epidemic. Patients were distributed in eight distinct departments. Some of them were Respiratory Medicine Departments, with the rest being Infectious Diseases Departments. Among these departments, five participated in this analysis. Pammakaristos, a 160bed tertiary hospital, was assigned as a COVID-19 exclusive unit for the needs of the pandemic and only its 31-bed Infectious Diseases Department remained active at this period.

Objectives. We sought to study the potential beneficial effects of different dosages of anticoagulation treatment on the prognosis of COVID-19 inpatients and on coagulation and inflammatory biomarkers as well as to evaluate the safety profile of this therapeutic strategy.

Data collection. Medical records were used to extract the data used in the present analysis, including demographics, clinical and laboratory parameters, therapeutical interventions, and outcomes. We recorded the following parameters: age, gender, smoking history, history of hypertension, history of diabetes mellitus (DM), oxygen saturation $\left(\mathrm{SO}_{2}\right)$, systolic blood pressure, Wells score (32), Charlson Comorbidity Index (CCI) score (33), and characteristics of the antithrombotic therapy.

Inclusion criteria were: (i) hospitalized in general wards COVID19 adult patients with full data for the aforementioned variables, and (ii) initiation of anticoagulation therapy within the first 5 days postadmission for those categorized as treated. Exclusion criteria were: (i) lack of data regarding variables of interest, (ii) contraindications to anticoagulant therapy e.g. active bleeding, and (iii) VTE or intubation or death within the first 24 hours post-admission.

Data were collected from patients' charts anonymously. The study was approved by the Institutional Ethical Committee of the Hospital and a waiver was obtained for informed consent for patients that were unable to provide a signed consent. Each department was responsible for the data entry of its patients. Nine of the Authors (KGK, VR, IT, KL, CT, MA, TV, ED, GP) were responsible for the evaluation of the quality of entered data, data interpretation in cases of uncertainty and communication with physicians of participating departments for additional information.

Blood sampling was performed during the disease course from 15 patients on intermediate dosage of low molecular weight heparin (LMWH). Concentrations of ferritin, interleukin-6 (IL-6) and interferon-gamma (IFN $\gamma$ ), which are markers that have been shown to be decreased by heparin in previous publications (22-25), were measured in serum using an enzyme immunosorbent assay (R\&D Systems Inc., Minneapolis, MN, USA). The lower limits of detection were: $15 \mathrm{pg} / \mathrm{ml}$ for ferritin; $10 \mathrm{pg} / \mathrm{ml}$ for IL-6; and $18 \mathrm{pg} / \mathrm{ml}$ for IFN $\gamma$.

ETHRA anticoagulation protocol for hospitalized COVID-19 patients. A written protocol of Enhanced dose THRomboprophylaxis (intermediate dose) in all COVID-19 Admissions (ETHRA) was developed by the $3^{\text {rd }}$ Department of Medicine and was distributed locally on March 11, 2020 to collaborating departments of Sotiria General Hospital. The protocol was revised on March 25, 2020 to include guidance in case of DIC or other significant clinical conditions (Figure 1).

A personalized approach was adopted according to different laboratory and clinical factors, such as obesity and/or impaired renal function. Treatment options included LMWH or fondaparinux (Figure 1). Four of the Authors (GP, ED, AK, EK) served as consultants throughout the Hospital's departments and communicated the ETHRA anticoagulation protocol among staff meetings for the management of COVID-19 patients. Treating physicians in other departments either adopted the ETHRA protocol or complied with the national recommendations issued on April 16 and 29,2020, arguing for prophylactic dose of anticoagulation treatment in all hospitalized COVID-19 patients $(30,31)$.

Primary and secondary outcomes. We adopted a composite primary outcome, as adopted previously in other important trials (34). Primary endpoint consisted of intubations or VTE or deaths during a follow-up of at least 14 hospitalization days. VTE included pulmonary embolism (PE) and deep vein thrombosis (DVT) confirmed with imaging. Leg doppler ultrasound was performed upon clinical suspicion. A low threshold of suspicion for pulmonary embolism was maintained; imaging with computed tomography pulmonary angiogram (CTPA) was performed. CTPA was ordered 


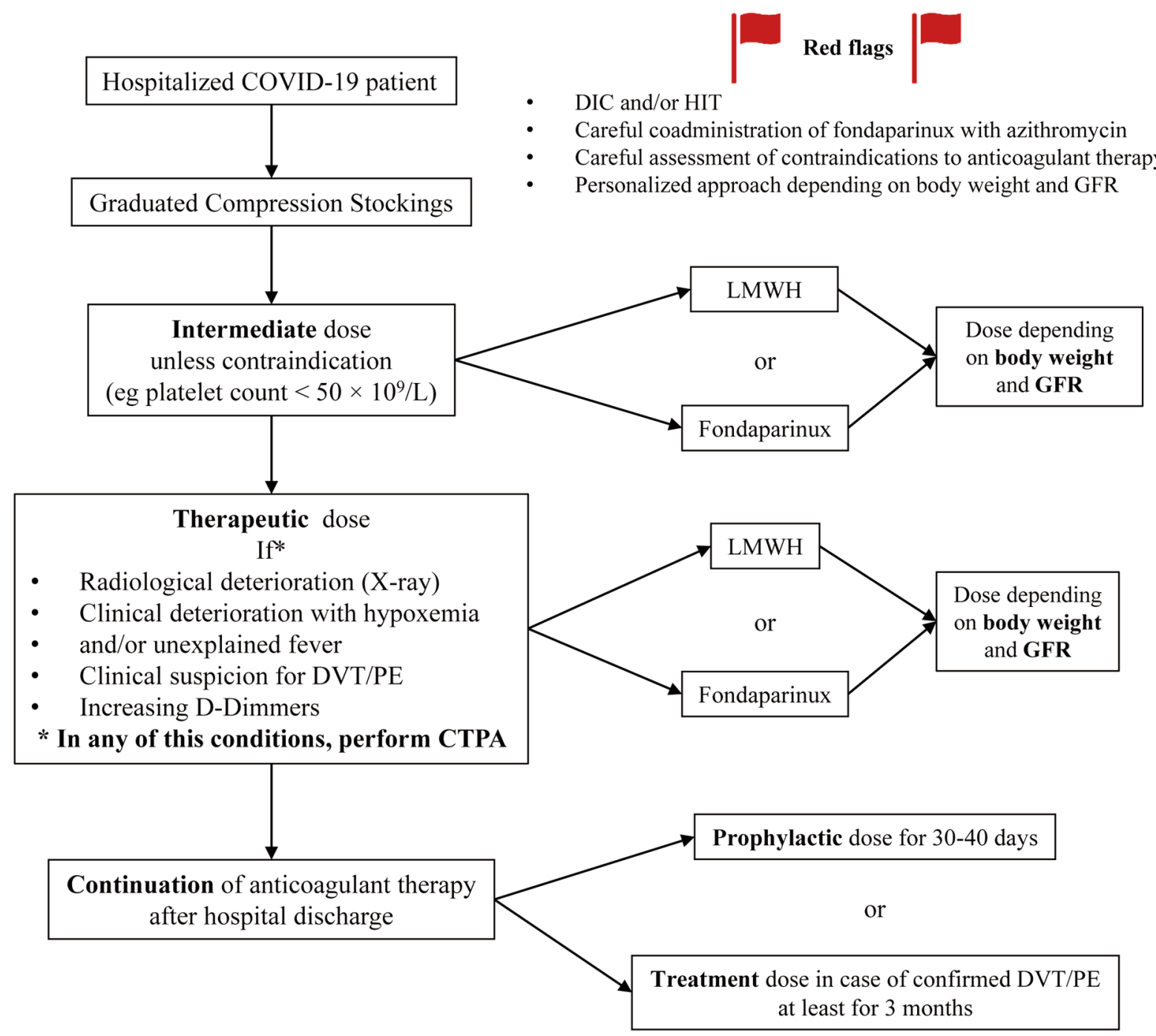

Figure 1. Protocol of Enhanced dosage THRomboprophylaxis in all patients Admitted (ETHRA) for COVID-19 in medical wards. DIC: Disseminated intravascular coagulation; DVT: deep vein thrombosis; GFR: glomerular filtration rate; HIT: heparin induced thrombocytopenia; LMWH: low molecular weight heparin; PE: pulmonary embolism; q.d.: once a day.

in every case of patients' clinical deterioration post-admission (i.e. deterioration of respiratory function, relapse of fever or persistence of fever after five days of hospitalization, increase in D-Dimers or decrease in platelet count compared to admission values) (Figure 1). Secondary outcomes included: (i) inflammatory biomarkers in patients treated with intermediate dosage $v s$. those treated with other (or no) anticoagulation regimens; and (ii) safety of anticoagulation treatment measured as incidence of bleeding events, heparininduced thrombocytopenia (HIT) (35) or allergic reactions.

Statistical analysis. Descriptive statistics (counts and percentages) were used for categorical variables. Means [standard deviation (SD)] were used for normally distributed data and median [interquartile range (IQR): $25^{\text {th }}$ percentile to $75^{\text {th }}$ percentile] for data not normally distributed. Chi-square test was used for comparison of percentages and one-way ANOVA or Kruskal-Wallis test for comparison of quantitative variables across categories of antithrombotic treatment, as appropriate. A Cox regression analysis was performed for identifying determinants of the cumulative incidence of the endpoint in the whole population. Category of antithrombotic therapy was entered in the model, whereas age, gender, smoking, history of hypertension, history of diabetes, baseline $\mathrm{SO}_{2}$, baseline systolic blood pressure, Wells score, CCI score were selected according to stepwise process (entry probability: 0.05, removal: 0.1). Hazard ratios [95\% confidence intervals (CI)] were reported for the variables retained in the final model. Comparison between hazard ratios was performed using test of interaction (z-score).

Regarding the cytokine biomarker analysis, patients were divided into two groups: (i) those for which sampling was performed before the start of LMWH; and (ii) those for which sampling was done more than 3 days after the start of LMWH. A group of four 
in vivo $35: 653-661(2021)$

Table I. Demographics and clinical characteristics of patients included in the ETHRA study.

\begin{tabular}{|c|c|c|c|c|c|c|}
\hline \multirow[t]{2}{*}{ Variable } & \multirow[b]{2}{*}{$\begin{array}{l}\text { Total sample } \\
\quad(\mathrm{n}=95)\end{array}$} & \multicolumn{5}{|c|}{ Category of antithrombotic therapy } \\
\hline & & $\begin{array}{l}\text { No prophylaxis } \\
(\mathrm{n}=15)\end{array}$ & $\begin{array}{l}\text { Prophylaxis } \\
\quad(\mathrm{n}=26)\end{array}$ & $\begin{array}{l}\text { Intermediate } \\
\quad(n=42)\end{array}$ & $\begin{array}{l}\text { Therapeutic } \\
(\mathrm{n}=12)\end{array}$ & $p$-Value \\
\hline Age (years) & $59.5(19.1)$ & $53.7(15.2)$ & $56.8(20.1)$ & $58.5(18.3)$ & $76(16.4)$ & 0.01 \\
\hline Males & $58(61.1)$ & $8(53.3)$ & $14(53.8)$ & $30(71.4)$ & $6(50)$ & NS \\
\hline Smoking & $20(21.1)$ & $3(20)$ & $7(26.9)$ & $9(21.4)$ & $1(8.3)$ & NS \\
\hline Hypertension & $26(27.4)$ & $2(13.3)$ & $5(19.2)$ & $15(35.7)$ & $4(33.3)$ & NS \\
\hline Diabetes & $8(8.4)$ & $0(0)$ & $3(11.5)$ & $3(7.1)$ & $2(16.7)$ & NS \\
\hline $\mathrm{SBP}(\mathrm{mmHg})$ & $120(110,140)$ & $120(110,135)$ & $120(103.8,137.8)$ & $120(110,140)$ & $120(110,140)$ & NS \\
\hline O2 Saturation (\%) & $96(95,97)$ & $95(95,96)$ & $96(95,97)$ & $96(94,98)$ & $95.5(93.3,97.5)$ & NS \\
\hline Wells score & $0(0,1)$ & $0(0,1.5)$ & $0(0,0)$ & $0(0,0)$ & $0(0,1.5)$ & NS \\
\hline Charlson Comorbidity index & $2.0(0,4)$ & $1(0,3)$ & $2(0,3.3)$ & $2(0,3)$ & $5(5,7.5)$ & $<0.001$ \\
\hline Hydroxychloroquine & $70(74)$ & $9(60)$ & $21(81)$ & $33(79)$ & $7(58)$ & NS \\
\hline Azithromycin & $81(85)$ & $12(80)$ & $23(88)$ & $38(90)$ & $8(67)$ & NS \\
\hline Other antibiotics & $79(83)$ & $11(73)$ & $23(88)$ & $35(83)$ & $10(83)$ & NS \\
\hline Lopinavir/Ritonavir & $13(14)$ & $3(20)$ & $2(8)$ & $6(14)$ & $2(17)$ & NS \\
\hline Remdesivir & $1(1)$ & $0(0)$ & $0(0)$ & $1(2)$ & $0(0)$ & NS \\
\hline СТРА & $6(6)$ & $0(0)$ & $1(4)$ & $4(10)$ & $1(8)$ & NS \\
\hline
\end{tabular}

Values are presented as numbers (percentage), mean (SD) or median (interquartile range); CTPA: computed tomography pulmonary angiogram; NS: non-significant. Bold values indicate statistical significance.

inpatients with uncomplicated COVID-19 that did not participate in the analysis cohort were used as controls. Comparisons were done by ANOVA test.

Statistical package IBM SPSS Statistics for Windows, Version 21.0. (IBM Corp, Armonk, NY, USA) was used. Statistical significance was set at 0.05 level.

\section{Results}

We studied 127 patients with COVID-19 who were admitted to two collaborating Hospitals (Sotiria and Pammakaristos Hospitals, Athens, Greece). Among them, 95 patients (males $61 \%$ ) fulfilled the inclusion criteria and were further analyzed. Basic demographics of the cohort are shown in Table I.

Implementation of the ETHRA anticoagulation protocol. Patients included in our study were treated in five Departments of Sotiria Hospital, but only in two in full compliance with the ETHRA protocol, whereas in the rest of the departments, thromboprophylaxis was administered at the physician's discretion, based on perceived patient's individual risk and currently available national and international recommendations.

Demographics and treatment characteristics. Eighty of the 95 patients of the cohort (84\%) were administered anticoagulant treatment. Patients were divided in four groups; Group A, no anticoagulation ( $\mathrm{n}=15$, patients without identified risk factors for VTE during the very early era of admissions); Group B, prophylactic dose $(n=26)$; Group $C$, intermediate dosage $(n=42)$; Group D, therapeutic dosage $(n=12)$. Among Group D, eleven patients were switched from oral medication for preexisting indications (e.g. atrial fibrillation, thrombophilia) to LMWH or fondaparinux, whereas the $12^{\text {th }}$ patient was placed on therapeutic LMWH due to atrial fibrillation diagnosed upon admission. No significant differences were observed in baseline characteristics among groups, except for age and CCI which were higher in Group D $(p<0.05)$ (Table I). Patients received enoxaparin (56 patients, $70 \%$ ), tinzaparin (13 patients, $16 \%$ ) or fondaparinux (11 patients, 14\%).

Primary and secondary end points. We observed 21 events (17 intubations, 4 deaths) during a median follow-up of 13 (6, 14) days. Distribution of events per anticoagulation treatment group was: Group A, 6 of 15 patients (40\%) (including 1 death); Group B, 5 of 26 patients (19\%) (including 1 death); Group C, 6 of 42 patients (14\%); and Group D, 4 of 12 patients (33\%) (including 2 deaths). The rate of events in Group A (no anticoagulation) was significantly higher than that in Group C (intermediate dose) $(p=0.04)$.

The median (IQR) hospitalization days of the antithrombotic therapy initiation for those reaching the primary end point was 1 ( 0,1 days), which was comparable to that of the rest of the cohort $[1(1,1)$ days, $p=0.17$ for comparison]. The median time interval (IQR) in days from symptoms onset to admission was $8(5,10)$ [with outcome events $8(5.5,9)$; without events: $8(5,10.3), p=0.74)]$.

We recorded only three patients (3\%) with minor hemorrhagic complications as possible side effects of the 
Table II. Hazard ratios for the variables predicting outcome in Cox regression analysis.

\begin{tabular}{lcc}
\hline Variable & $\begin{array}{c}\text { Hazard Ratio }(95 \% \mathrm{CI}) \\
\text { for outcome }\end{array}$ & $p$-Value \\
\hline Age & $1.07(1.03,1.11)$ & 0.001 \\
$\mathrm{O}_{2}$ Saturation & $0.86(0.74,0.99)$ & $<0.05$ \\
Thromboprophylaxis $v s$. none & $0.34(0.10,1.17)$ & $\mathrm{NS}$ \\
Intermediate $v s$. none & $0.16(0.05,0.52)$ & $<0.05$ \\
Therapeutic $v s$. none & $0.17(0.04,0.71)$ & $<0.05$ \\
\hline
\end{tabular}

NS: Non-significant.

anticoagulant drugs (1 epistaxis, 2 hemoptysis); 2 of them under intermediate and 1 under prophylactic dosage. None of them required discontinuation of the anticoagulation treatment.

In Cox-regression analysis, age, baseline $\mathrm{SO}_{2}$ and use of antithrombotic treatment were associated with the cumulative incidence of the primary endpoint (Table II). A significant reduction of events with the use of either intermediate [hazard ratio $(\mathrm{HR})=0.16 \quad(0.05-0.52), p=0.002] \quad$ or therapeutic anticoagulation dose [HR=0.17 (0.04-0.71), $p=0.015]$, with HRs being comparable ( $p=\mathrm{NS}, \mathrm{z}$-test). Cumulative incidence of the primary endpoint in each category of antithrombotic treatment is shown in Figure 2. Higher age and lower baseline $\mathrm{SO}_{2}$ were associated with a higher incidence of the primary endpoint.

Serial D-dimer values were available in 69 patients. Baseline and end of follow-up values were higher in those reaching the primary endpoint $(\mathrm{n}=8)$ [baseline: $1.79(0.57$ $3.23) v s .0 .64(0.39-1.11)$ and $1.62(0.87-2.83) v s .0 .62(0.39-$ $1.15) \mathrm{mg} / \mathrm{l}$, respectively, $p<0.05$ for both comparisons).

Inflammatory biomarker values were measured in 15 patients with intermediate anticoagulation dose. Ferritin levels were increased before the initiation of LMWH and decreased with treatment at levels similar to untreated controls (Figure 3). No significant differences were detected between treatment groups in the other tested biomarkers (Figure 3).

\section{Discussion}

This study investigated the effectiveness of different dosages of anticoagulation treatment in the prevention of potentially life-threatening complications in COVID-19 patients admitted in medical wards, in view of a possible inhibition of both the coagulation and inflammatory cascade. The key elements of the employed ETHRA protocol were: (i) administration at least of thromboprophylaxis in all inpatients, irrespective of their individual risk of VTE, (ii) adoption and preference of intermediate dosage, and (iii) maintenance of a low threshold for suspicion of pulmonary embolism with prompt switch to full anticoagulation upon laboratory or clinical deterioration, while waiting for a CTPA imaging. Patients treated with intermediate anticoagulation doses in our cohort showed the lowest incidence of the primary endpoint which were almost 3 -fold less than those observed without anticoagulation (40\% vs. $14 \%, p=0.04)$. Cox regression analysis showed a similar effect of intermediate dose with full-therapeutic dose anticoagulation in the reduction of the HR, albeit the latter group had more comorbidities, as depicted by the significantly higher CCI. Patients received full therapeutic dose for pre-existing indications and may constitute a distinct category compared to those administered intermediate dose in the context of COVID-19 management. However, they were included in the regression analysis and showed an unexpectedly better survival.

Early into the COVID-19 pandemic (36), there has been a great concern about the tendency of the SARS-CoV-2 to cause hypercoagulable and potentially fatal complications, in addition to its recognized inflammatory features $(12,15-17)$. Two mechanisms have already been recognized as major contributors to potentially fatal COVID-19 associated events; first, the endothelial injury that promotes local vessel thrombosis particularly affecting the lung and second, the DIC triggered by SARS-CoV-2 itself $(6,10,12,14-20,37)$. We hypothesized that timely and adequate anticoagulant treatment with LMWH could possibly avert adverse outcomes mediated by both catastrophic mechanisms $(21,22,26-28)$. Notably the Wells Score was universally low in our cohort, revealing no classical risk factors for VTE across all four groups.

Our decision to treat all COVID-19 inpatients with enhanced thromboprophylaxis (intermediate dosage) was made before international and national recommendations arguing for standard thromboprophylaxis only in severely ill hospitalized COVID-19 patients (29-31). Our concerns about their increased risk for VTE was based on our previous experience with sudden deaths caused by pulmonary embolism in the context of H1N1 and the clinical profile of the first COVID-19 admissions, including immobilization due to lockdown restrictions, dehydration due to fever, increased age and comorbidities (26-28).

Our data suggest that higher dosage of anticoagulation was associated with better outcomes compared to standard prophylactic dosage. This survival benefit seems to be exerted without preventing PE, since no such events were recorded in our cohort, despite high level of suspicion. Diagnosis of pulmonary embolism in the setting of SARSCoV-2 pneumonia may be extremely challenging, largely due to an overlap of clinical symptoms and the unknown performance of CTPA in the presence of solely microvascular infarcts $(38,39)$. Post-mortem examinations revealed microthrombi in alveolar capillaries in $50 \%$ of COVID-19 patients (37). Vascular dysfunction was also prominent in other organs $(10,37)$. Interestingly, coagulation disorders have been observed also in former coronavirus infections such as SARS-CoV-1 and MERS-CoV (40). 


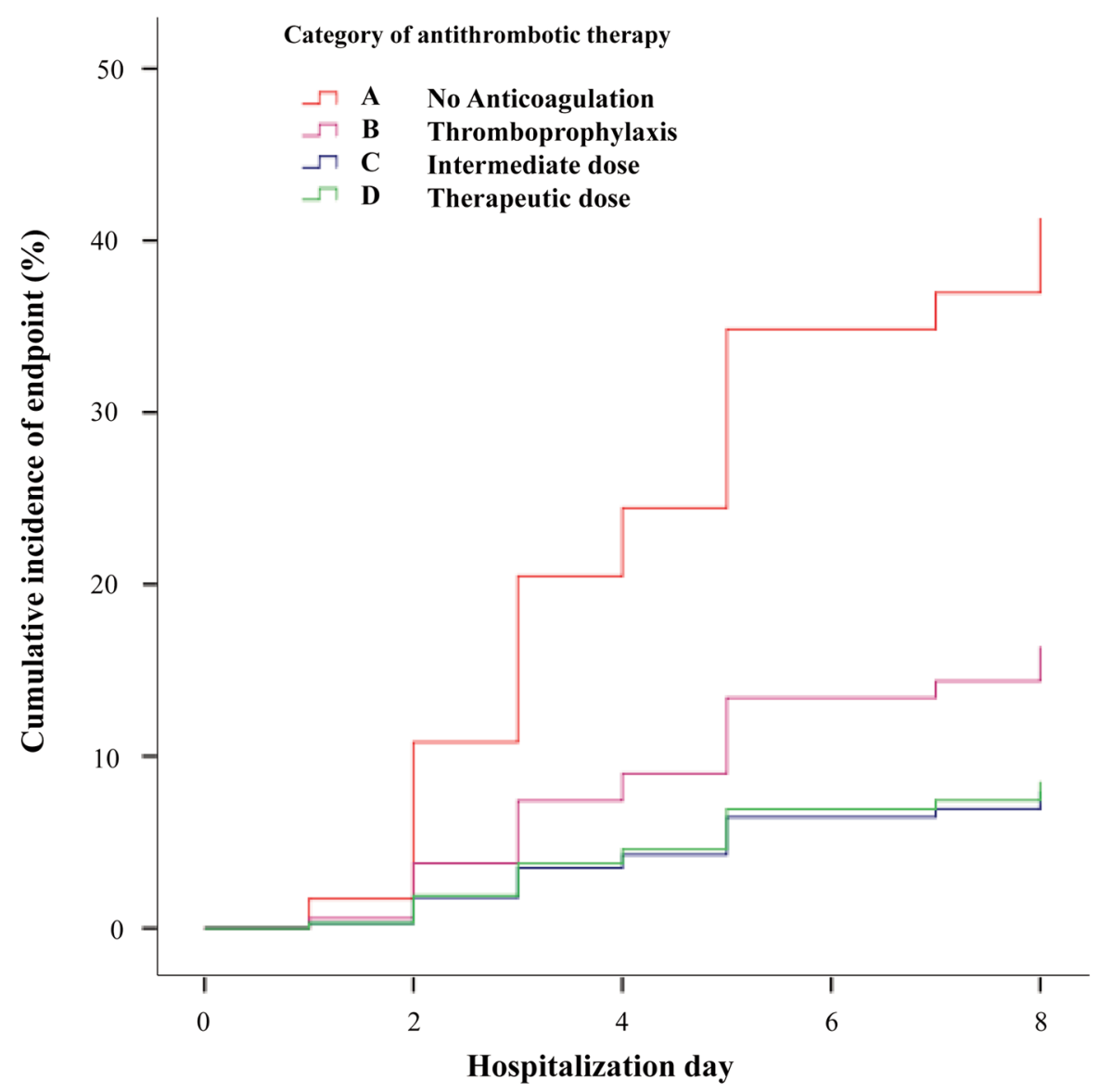

Figure 2. Cumulative incidence of events (VTE or intubation or death) per therapeutic anticoagulation Group.

Elevated D-Dimers have been used among other parameters as early indicators of imminent serious cardiovascular complications $(15,18-20)$. However, in our cohort, baseline average values of D-Dimers, PT and fibrinogen were not alarming and/or decreased during hospitalization, whereas only patients who subsequently developed major events showed elevated D-Dimer values. These findings are in line with findings of other studies (41, 42). Early administration of adequate anticoagulation treatment to prevent VTE episodes or treat episodes not yet apparent (e.g. in small vessels), may avert high concentrations of D-Dimers, PT, and fibrinogen. In line with our data, a study has reported the effectiveness of therapeutic anticoagulation treatment in mechanically ventilated COVID-19 patients (43). In our study employing medical ward patients, intermediate dose anticoagulation seems to be adequate, with obvious benefit in terms of toxicity risks. As far as inflammatory markers are concerned, severe COVID19 is accompanied by hyperferritenemia (44). Treatment with intermediate dose anticoagulation decreased ferritin within values measured in comparators with mild infection.
Whether this is due to a direct anti-inflammatory effect of heparin remains to be elucidated.

Concerning the secondary safety outcome only three minor bleeding events (two with intermediate and one with prophylactic dosage) were observed, which did not mandate withdrawal of anticoagulation treatment. No allergy or HeparinInduced Thrombocytopenia (HIT) events were recorded (45).

Findings of the present study should be interpreted in the light of several limitations. First, the retrospective nature of the study poses a certain limitation. However, it is one of the few studies in which anticoagulation was administered through a purpose-constructed algorithm from the onset of the epidemic in our settings. Second, we did not have frequent measurements of the coagulation parameters and cytokines, that could enable us to show their kinetics. Although a clear limitation, this is a realistic reflection of the current clinical practice. Low median value of D-Dimers on admission, verify that there was no trigger for the clinician to perform frequent repeat measurements. Early admission of our patients regarding the onset of symptoms (median 8 days in our cohort), is probably attributed to the availability of beds in 


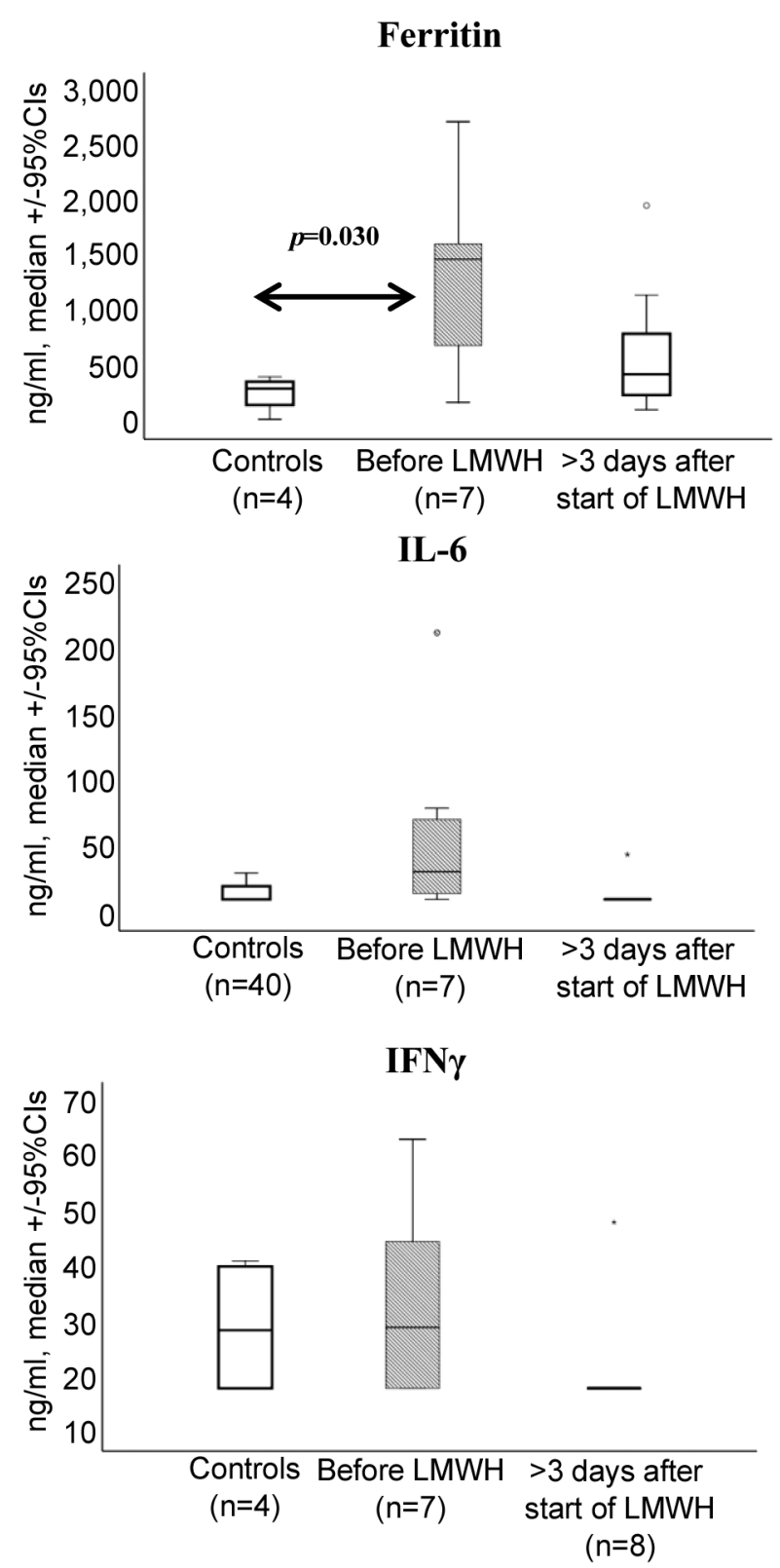

Figure 3. Concentrations of ferritin, interleukin-6 (IL-6) and interferongamma $(I F N \gamma)$ in the circulation of seven patients before the start of treatment with LMWH and of eight patients more than 3 days after start of the treatment with LMWH. Concentrations from four patients with mild COVID-19 are provided as controls. Only significant comparisons are provided.

our country and might have been a contributor to early management of life-threatening events. In support, the median D-Dimer values of patients who developed events were comparable to those reported through the literature (37).

Concerning the strengths of the present study, it was based on a representative sample of patients in Athens Metropolitan area with the inclusion of reference hospitals exclusive for the management of COVID-19. The population of the study, consisting of non-severely ill patients upon admission makes our observations important in terms of potential prevention of life-threatening complications in mild or moderate COVID-19 illness. Taking into consideration emerging evidence (23-25, $44,45)$, we hypothesize that anticoagulation treatment may contribute to better outcomes in COVID-19 patients by inhibiting both coagulation and inflammatory cascade. Future prospective randomized trials are needed to confirm this hypothesis.

\section{Conclusion}

Anticoagulation treatment (especially intermediate dosage) in COVID-19 inpatients was significantly associated with less life-threatening events. Our hypothesis is that anticoagulation treatment interferes with COVID-19 by early treatment/ inhibition of both coagulation and inflammatory cascades.

\section{Conflicts of Interest}

The Authors declare no conflicts of interest related to this study.

\section{Authors' Contributions}

Conception and design: GP, ED, AK, KGK, IB, EM, EG, EM, KS; Analysis and interpretation: GP, ED, KGK, VR, IT, CT, MA, TV, KL, EK, KA, KD, GT, AR; Data collection: GP, ED, KGK, VR, IT, CT, MA, TV, KL, EM; Writing the article: GP, ED, AK, KGK, EM, EG, EM; Critical revision of the article: GP, ED, AK, KGK, VR, IT, CT, MA, TV, KL, EK, KA, IB, EM, EG, KD, GT, AR, EDM, KS; Final approval of the article: GP, ED, AK, KGK, VR, IT, CT, MA, TV, KL, EK, KA, IB, EM, EG, KD, GT, AR, EDM, KS; Statistical analysis: GP, AK, KGK, VR, IT, MA, EM, EG.

\section{References}

1 Zhou P, Yang XL, Wang XG, Hu B, Zhang L, Zhang W, Si HR, Zhu Y, Li B, Huang CL, Chen HD, Chen J, Luo Y, Guo H, Jiang RD, Liu MQ, Chen Y, Shen XR, Wang X, Zheng XS, Zhao K, Chen QJ, Deng F, Liu LL, Yan B, Zhan FX, Wang YY, Xiao GF and Shi ZL: A pneumonia outbreak associated with a new coronavirus of probable bat origin. Nature 579: 270-273, 2020. PMID: 32015507. DOI: 10.1038/s41586-020-2012-7

2 Chen N, Zhou M, Dong X, Qu J, Gong F, Han Y, Qiu Y, Wang J, Liu Y, Wei Y, Xia J, Yu T, Zhang X and Zhang L: Epidemiological and clinical characteristics of 99 cases of 2019 novel coronavirus pneumonia in Wuhan, China: a descriptive study Lancet 395: 507-513, 2020. PMID: 32007143. DOI: 10.1016/S0140-6736(20)30211-7

3 Worldometers. Available at: https://www.worldometers.info/ coronavirus/?utm_campaign=homeAdUOA?Si [Last accessed on October 7, 2020]

4 Greek National Public Heath Organism. Available at: https://eody.gov.gr/schedio-stadiakis-apoklimakosis-gefyraasfaleias-28-04-2020/ [Last accessed on October 7, 2020] 
5 Greek National Public Heath Organism (daily press release). Available at: https://eody.gov.gr/0705_briefing_covid19/[Last accessed on October 7, 2020]

6 Huang C, Wang Y, Li X, Ren L, Zhao J, Hu Y, Zhang L, Fan G, Xu J, Gu X, Cheng Z, Yu T, Xia J, Wei Y, Wu W, Xie X, Yin W, Li H, Liu M, Xiao Y, Gao H, Guo L, Xie J, Wang G, Jiang R, Gao Z, Jin Q, Wang J and Cao B: Clinical features of patients infected with 2019 novel coronavirus in Wuhan, China. Lancet 395: 497-506, 2020. PMID: 31986264. DOI: 10.1016/S01406736(20)30183-5

7 Xiong TY, Redwood S, Prendergast B and Chen M: Coronaviruses and the cardiovascular system: acute and longterm implications. Eur Heart J 41: 1798-1800, 2020. PMID: 32186331. DOI: 10.1093/eurheartj/ehaa231

8 Zhang $\mathrm{H}$, Penninger JM, Li Y, Zhong $\mathrm{N}$ and Slutsky AS: Angiotensin-converting enzyme 2 (ACE2) as a SARS-CoV-2 receptor: molecular mechanisms and potential therapeutic target. Intensive Care Med 46: 586-590, 2020. PMID: 32125455. DOI: 10.1007/s00134-020-05985-9

9 Driggin E, Madhavan MV, Bikdeli B, Chuich T, Laracy J, Biondi-Zoccai G, Brown TS, Der Nigoghossian C, Zidar DA, Haythe J, Brodie D, Beckman JA, Kirtane AJ, Stone GW, Krumholz HM and Parikh SA: Cardiovascular considerations for patients, health care workers, and health systems during the COVID-19 pandemic. J Am Coll Cardiol 75: 2352-2371, 2020. PMID: 32201335. DOI: 10.1016/j.jacc.2020.03.031

10 Wichmann D, Sperhake JP, Lütgehetmann M, Steurer S, Edler C, Heinemann A, Heinrich F, Mushumba H, Kniep I, Schröder AS, Burdelski C, de Heer G, Nierhaus A, Frings D, Pfefferle S, Becker H, Bredereke-Wiedling H, de Weerth A, Paschen HR, Sheikhzadeh-Eggers S, Stang A, Schmiedel S, Bokemeyer C, Addo MM, Aepfelbacher M, Püschel K and Kluge S: Autopsy findings and venous thromboembolism in patients with COVID19. Ann Intern Med 173: 268-277, 2020. PMID: 32374815. DOI: 10.7326/M20-2003

11 Fogarty H, Townsend L, Ni Cheallaigh C, Bergin C, MartinLoeches I, Browne P, Bacon CL, Gaule R, Gillett A, Byrne M, Ryan K, O'Connell N, O'Sullivan JM, Conlon N and O'Donnell JS: COVID-19 coagulopathy in Caucasian patients. Br J Haematol 189: 1044-1049, 2020. PMID: 32330308. DOI: 10.1111/bjh.16749

12 Tang N, Li D, Wang X and Sun Z: Abnormal coagulation parameters are associated with poor prognosis in patients with novel coronavirus pneumonia. J Thromb Haemost 18: 844-847, 2020. PMID: 32073213. DOI: $10.1111 /$ jth. 14768

13 Fan BE, Chong VCL, Chan SSW, Lim GH, Lim KGE, Tan GB, Mucheli SS, Kuperan P and Ong KH: Hematologic parameters in patients with COVID-19 infection. Am J Hematol 95: E131E134, 2020. PMID: 32129508. DOI: 10.1002/ajh.25774

14 Han H, Yang L, Liu R, Liu F, Wu KL, Li J, Liu XH and Zhu CL: Prominent changes in blood coagulation of patients with SARS-CoV-2 infection. Clin Chem Lab Med 58: 1116-1120, 2020. PMID: 32172226. DOI: 10.1515/cclm-2020-0188

15 Zhou F, Yu T, Du R, Fan G, Liu Y, Liu Z, Xiang J, Wang Y, Song B, Gu X, Guan L, Wei Y, Li H, Wu X, Xu J, Tu S, Zhang Y, Chen $\mathrm{H}$ and $\mathrm{Cao} \mathrm{B}$ : Clinical course and risk factors for mortality of adult inpatients with COVID-19 in Wuhan, China: a retrospective cohort study. Lancet 395: 1054-1062, 2020. PMID: 32171076. DOI: 10.1016/S0140-6736(20) 30566-3
16 Bikdeli B, Madhavan MV, Jimenez D, Chuich T, Dreyfus I, Driggin E, Nigoghossian C, Ageno W, Madjid M, Guo Y, Tang LV, Hu Y, Giri J, Cushman M, Quéré I, Dimakakos EP, Gibson CM, Lippi G, Favaloro EJ, Fareed J, Caprini JA, Tafur AJ, Burton JR, Francese DP, Wang EY, Falanga A, McLintock C, Hunt BJ, Spyropoulos AC, Barnes GD, Eikelboom JW, Weinberg I, Schulman S, Carrier M, Piazza G, Beckman JA, Steg PG, Stone GW, Rosenkranz S, Goldhaber SZ, Parikh SA, Monreal M, Krumholz HM, Konstantinides SV, Weitz JI and Lip GYH; Global COVID-19 Thrombosis Collaborative Group, Endorsed by the ISTH, NATF, ESVM, and the IUA, Supported by the ESC Working Group on Pulmonary Circulation and Right Ventricular Function: COVID-19 and thrombotic or thromboembolic disease: implications for prevention, antithrombotic therapy, and follow-up. J Am Coll Cariol 75: 2950-2973, 2020. PMID: 32311448. DOI: 10.1016/j.jacc.2020.04.031

17 Klok FA, Kruip MJHA, van der Meer NJM, Arbous MS, Gommers DAMPJ, Kant KM, Kaptein FHJ, van Paassen J, Stals MAM, Huisman MV and Endeman H: Incidence of thrombotic complications in critically ill ICU patients with COVID-19. Thromb Res 191: 145-147, 2020. PMID: 32291094. DOI: 10.1016/j.thromres.2020.04.013

18 Lippi G and Plebani M: Laboratory abnormalities in patients with COVID-2019 infection. Clin Chem Lab Med 58: 1131-1134, 2020. PMID: 32119647. DOI: 10.1515/cclm-2020-0198

19 Lippi G, Plebani M and Michael Henry B: Thrombocytopenia is associated with severe coronavirus disease 2019 (COVID-19) infections: A meta-analysis. Clin Chim Acta 506: 145-148, 2020. PMID: 32178975. DOI: 10.1016/j.cca.2020.03.022

20 Lippi G and Favaloro EJ: D-dimer is associated with severity of coronavirus disease 2019 (COVID-19): a pooled analysis. Thromb Haemost 120: 876-878, 2020. PMID: 32246450. DOI: 10.1055/s0040-1709650

21 Young E: The anti-inflammatory effects of heparin and related compounds. Thromb Res 122: 743-752, 2008. PMID: 17727922. DOI: $10.1016 /$ j.thromres.2006.10.026

22 Cassinelli G and Naggi A: Old and new applications of nonanticoagulant heparin. Int J Cardiol 212: 14-21, 2016. PMID: 27264866. DOI: 10.1016/S0167-5273(16)12004-2

23 Hogwood J, Pitchford S, Mulloy B, Page C and Gray E: Heparin and non-anticoagulant heparin attenuate histone-induced inflammatory responses in whole blood. PLoS One 15: e0233644, 2020. PMID: 32469940. DOI: 10.1371/journal.pone.0233644

24 Belen-Apak FB and Sarialioglu F: The old but new: Can unfractioned heparin and low molecular weight heparins inhibit proteolytic activation and cellular internalization of SARS-CoV2 by inhibition of host cell proteases? Med Hypotheses 142: 109743, 2020. PMID: 32335456. DOI: 10.1016/j.mehy.2020. 109743

25 Alkhoury H, Hautmann A, Fuhrmann B, Syrowatka F, Erdmann F, Zhou G, Stojanović S, Najman S and Groth T: Studies on the mechanisms of anti-inflammatory activity of heparin- and hyaluronan-containing multilayer coatings-targeting NF- $x \mathrm{~B}$ signalling pathway. Int J Mol Sci 21: 3724, 2020. PMID: 32466274. DOI: $10.3390 /$ ijms21103724

26 Dimakakos E, Grapsa D, Vathiotis I, Papaspiliou A, Panagiotarakou M, Manolis E and Syrigos K: H1N1-induced venous thromboembolic events? results of a single-institution case series. Open Forum Infect Dis 3: ofw214, 2016. PMID: 28018924. DOI: $10.1093 /$ ofid/ofw214 
27 Kollias A, Kyriakoulis KG, Dimakakos E, Poulakou G, Stergiou GS and Syrigos K: Thromboembolic risk and anticoagulant therapy in COVID-19 patients: Emerging evidence and call for action. Br J Haematol 189: 846-847, 2020. PMID: 32304577. DOI: $10.1111 /$ bjh.16727

28 Schunemann HJ, Cushman M, Burnett AE, Kahn SR, BeyerWestendorf J, Spencer FA, Rezende SM, Zakai NA, Bauer KA, Dentali F, Lansing J, Balduzzi S, Darzi A, Morgano GP, Neumann I, Nieuwlaat R, Yepes-Nuñez JJ, Zhang Y and Wiercioch W: American Society of Hematology 2018 Guidelines for management of venous thromboembolism: prophylaxis for hospitalized and nonhospitalized medical patients. Blood Adv 2: 3198-3225, 2018. PMID: 30482763. DOI: 10.1182/bloodadvances.2018022954

29 Thachil J, Tang N, Gando S, Falanga A, Cattaneo M, Levi M, Clark $\mathrm{C}$ and Iba T: ISTH interim guidance on recognition and management of coagulopathy in COVID-19. J Thromb Haemost 18: 1023-1026, 2020. PMID: 32338827. DOI: 10.1111/jth.14810

30 National Public Health Organism: National therapeutic algorithm for COVID-19 patients including thromboprophylaxis recommendations issued on 16/4/2020. Available at: https://eody.gov.gr/neoskoronaios-covid-19/ [Last accessed on October 7, 2020]

31 Guidance on thromboprophylaxis for COVID-19 patients by the Hellenic Society of Haematology, issued April 29, 2020, updated July 20, 2020. Available at: https://eae.gr/el/information/news/item/924systaseis-thromvoprofylaksis-se-astheneis-me-covid-19-tmimaaimostasis-e-a-e [Last accessed on October 7, 2020]

32 Wells PS, Ginsberg JS, Anderson DR, Kearon C, Gent M, Turpie AG, Bormanis J, Weitz J, Chamberlain M, Bowie D, Barnes D and Hirsh J: Use of a clinical model for safe management of patients with suspected pulmonary embolism. Ann Intern Med 129: 9971005, 1998. PMID: 9867786. DOI: 10.7326/0003-4819-129-12199812150-00002

33 Charlson ME, Pompei P, Ales KL and MacKenzie CR: A new method of classifying prognostic comorbidity in longitudinal studies: development and validation. J Chronic Dis 40: 373-383, 1987. PMID: 3558716. DOI: 10.1016/0021-9681(87)90171-8

34 Geleris J, Sun Y, Platt J, Zucker J, Baldwin M, Hripcsak G, Labella A, Manson DK, Kubin C, Barr RG, Sobieszczyk ME and Schluger NW: Observational Study of Hydroxychloroquine in Hospitalized Patients with Covid-19. N Engl J Med 382: 2411-2418, 2020. PMID: 32379955. DOI: 10.1056/NEJMoa2012410

35 Patriarcheas V, Pikoulas A, Kostis M, Charpidou A and Dimakakos E: Heparin-induced thrombocytopenia: pathophysiology, diagnosis and management. Cureus 12: e7385, 2020. PMID: 32337112. DOI: 10.7759 /cureus. 7385

36 Declaration of COVID-19 as a pandemic by the WHO. Available at https://www.who.int/emergencies/diseases/novel-coronavirus2019 [Last Accessed on October 7, 2020]

37 Menter T, Haslbauer JD, Nienhold R, Savic S, Hopfer H, Deigendesch N, Frank S, Turek D, Willi N, Pargger H, Bassetti S, Leuppi JD, Cathomas G, Tolnay M, Mertz KD and Tzankov A: Post-mortem examination of COVID19 patients reveals diffuse alveolar damage with severe capillary congestion and variegated findings of lungs and other organs suggesting vascular dysfunction. Histopathology 77: 198-209, 2020. PMID: 32364264. DOI: $10.1111 /$ his.14134

38 Zuckier LS, Moadel RM, Haramati LB and Freeman L: Diagnostic evaluation of pulmonary embolism during the COVID-19 pandemic. J Nucl Med 61: 630-631, 2020. PMID: 32238427. DOI: 10.2967/jnumed.120.245571
39 Poissy J, Goutay J, Caplan M, Parmentier E, Duburcq T, Lassalle F, Jeanpierre E, Rauch A, Labreuche J and Susen S; Lille ICU Haemostasis COVID-19 Group. Pulmonary embolism in COVID-19 patients: Awareness of an increased prevalence. Circulation 142: 184-186, 2020. PMID: 32330083. DOI: 10.1161/CIRCULATIONAHA.120.047430

40 Giannis D, Ziogas IA and Gianni P: Coagulation disorders in coronavirus infected patients: COVID-19, SARS-CoV-1, MERS$\mathrm{CoV}$ and lessons from the past. J Clin Virol 127: 104362, 2020. PMID: 32305883. DOI: 10.1016/j.jcv.2020.104362

41 Ranucci M, Ballotta A, Di Dedda U, Bayshnikova E, Dei Poli M, Resta M, Falco M, Albano G and Menicanti L: The procoagulant pattern of patients with COVID-19 acute respiratory distress syndrome. J Thromb Haemost 18: 17471751, 2020. PMID: 32302448. DOI: 10.1111/jth.14854

42 Lodigiani C, Lapichino G, Carenzo L, Cecconi M, Ferrazzi P, Sebastian T, Kucher N, Studt JD, Sacco C, Bertuzzi A, Sandri MT and Barco S; Humanitas COVID-19 Task Force: Venous and arterial thromboembolic complications in COVID-19 patients admitted to an academic hospital in Milan, Italy. Thromb Res 191: 9-14, 2020. PMID: 32353746. DOI: 10.1016/j.thromres. 2020.04.024

43 Paranjpe I, Fuster V, Lala A, Russak AJ, Glicksberg BS, Levin MA, Charney AW, Narula J, Fayad ZA, Bagiella E, Zhao S and Nadkarni GN: Association of treatment dose anticoagulation with in-hospital survival among hospitalized patients with COVID-19. J Am Coll of Cardiol 76: 122-124, 2020. PMID: 32387623. DOI: $10.1016 /$ j.jacc.2020.05.001

44 Giamarellos-Bourboulis EJ, Netea MG, Rovina N, Akinosoglou K, Antoniadou A, Antonakos N, Damoraki G, Gkavogianni T, Adami ME, Katsaounou P, Ntaganou M, Kyriakopoulou M, Dimopoulos G, Koutsodimitropoulos I, Velissaris D, Koufargyris P, Karageorgos A, Katrini K, Lekakis V, Lupse M, Kotsaki A, Renieris G, Theodoulou D, Panou V, Koukaki E, Koulouris N, Gogos $\mathrm{C}$ and Koutsoukou A: Complex immune dysregulation in COVID-19 patients with severe respiratory failure. Cell Host Microbe 27: 992-1000.e3, 2020. PMID: 32320677. DOI: 10.1016/j.chom.2020.04.009

45 Bikdeli B, Madhavan MV, Gupta A, Jimenez D, Burton JR, Der Nigoghossian C, Chuich T, Nouri SN, Dreyfus I, Driggin E, Sethi S, Sehgal K, Chatterjee S, Ageno W, Madjid M, Guo Y, Tang LV, Hu Y, Bertoletti L, Giri J, Cushman M, Quéré I, Dimakakos EP, Gibson CM, Lippi G, Favaloro EJ, Fareed J, Tafur AJ, Francese DP, Batra J, Falanga A, Clerkin KJ, Uriel N, Kirtane A, McLintock C, Hunt BJ, Spyropoulos AC, Barnes GD, Eikelboom JW, Weinberg I, Schulman S, Carrier M, Piazza G, Beckman JA, Leon MB, Stone GW, Rosenkranz S, Goldhaber SZ, Parikh SA, Monreal M, Krumholz HM, Konstantinides SV, Weitz JI and Lip GYH; Global COVID-19 Thrombosis Collaborative Group: Pharmacological agents targeting thromboinflammation in COVID-19: Review and implications for future research. Thromb Haemost 120: 1004-1024, 2020. PMID: 32473596. DOI: 10.1055/s-0040-1713152

Received November 17, 2020

Revised December 3, 2020

Accepted December 4, 2020 